\title{
Thermal stress analysis of different full and ventilated disc brakes
}

\author{
C. Baron Saiz, T. Ingrassia, V. Nigrelli, V. Ricotta \\ Università degli Studi di Palermo, Dipartimento di Ingegneria Chimica, Gestionale, Informatica, Meccanica - 90128 Palermo, \\ Italy \\ tommaso.ingrassia@unipa.it
}

\begin{abstract}
During the braking phase, the heat produced by friction between pads and disc cannot be entirely dissipated. Consequently, the brake disc, especially if very hard braking occur, can accumulate large amounts of heat in a short time so producing high gradients of temperature on it. Under these conditions, functionality and safety of the brake system can be compromised.

The object of this study is to investigate, under extreme working conditions, the thermomechanical behaviour of different brake rotors in order to evaluate their efficiency and stability and to identify any compromising weakness on them. In particular, by means of FEM thermo-mechanical coupled analyses, one full disc and three ventilated rotors with different shapes have been studied. A very hard (fading) test has been used to evaluate the performances of the discs in terms of temperature distribution, stresses and strains. Obtained results demonstrate that the analysed ventilated discs, unlike the full rotor, can be effectively used in very hard working conditions, always ensuring high safety levels. Among the studied rotors, the curved-vanes disc was found to be the best solution.
\end{abstract}

KEYWORDS. Ventilated disc; Brake rotor; Thermomechanical analysis; FEM; Fade.

\section{INTRODUCTION}

$\mathrm{D}$ uring a braking, most of the kinetic energy of a car is converted into thermal energy due to the dry friction effects and, successively, the generated heat is dissipated in the surrounding environment [1-2]. For this reason, one of the main problem of a braking system is how to handle the thermal energy generated during its action. Although the heat dissipation mechanisms could be different (conduction, radiation and convection), the major portion of the generated heat flows out to the air and, consequently, it is dissipated by convection. However, on high-demand repeated braking applications, convection mechanism is unable to dissipate the great amount of incoming heat, so causing overheating of the components and inducing potential failures. Previous studies, in fact, showed that thermally induced cyclic stresses strongly affect the crack initiation in the brake discs [3]. Nakatsuji et al. [4] studied how cracks, which form around small holes in the flange of one-piece discs, propagate in overloading conditions, whereas Gao et al. analyzed the thermal fatigue fracture in brake discs [5-6]. High temperatures during braking, moreover, could cause the brake fade [7], which means losing both efficiency and security during the stopping process. High thermal loads, in fact, can determine considerable distortions of the brake rotor [8], so modifying the system response and increasing the brake judder propensity.

For all these reasons, increasing the thermal efficiency and the integrity of the brake components has become an essential objective in the modern automotive engineering field [9]. With this aim, innovative rotors have been designed to improve 
the convection mechanism of disc brakes [10-12], so to limit very high temperatures of the system. Ventilated disc brakes accomplish this purpose and, due to their braking stability, controllability and ability to provide a wide-range brake torque [10], they have been more and more used. Unlike full disks, they are designed with internal vanes that allow to drive greater amount of airflow through the disc. To continuously improve their performances, many new solutions have been proposed over the years by companies that produce disc brakes.

In this paper, different geometries of ventilated rotors have been studied to estimate their performances by means of thermo-mechanical coupled analyses. A full disc has been also analysed, in order to quantify the advantages of using air channels in hard braking conditions. The work has been developed as follows: in the first step, a reverse engineering procedure has been setup to create the parametric CAD models of the analysed disc brakes. In this phase, moreover, the geometries of the discs have been suitably modified to compare, in the most correct and consistent way, the results. In the second step, using the Ansys FEM code, brake-fading tests have been simulated through coupled thermal-structural analyses $[13,14]$. In the last step, the results of all the analysed brake discs have been studied and compared in terms of temperature, strain and stress distributions.

\section{WORKING CONDITIONS}

A im of this work is to evaluate the effectiveness, in terms of thermomechanical performances, of different internal configurations of ventilated brake rotors. To achieve this purpose, the analysed brake discs have been subjected to very hard conditions using the Brembo fading test [15-16]. This test consists of fourteen repeated braking, from an initial velocity, $\mathrm{Vi}$, of $160 \mathrm{~km} / \mathrm{h}(44.44 \mathrm{~m} / \mathrm{s})$ to stop, with a constant deceleration. Between two following braking, there is a recovery time during which the rotor is initially accelerated and, subsequently, maintained at constant velocity Vi. Fig. 1 shows the acceleration versus time graph during the fading test.

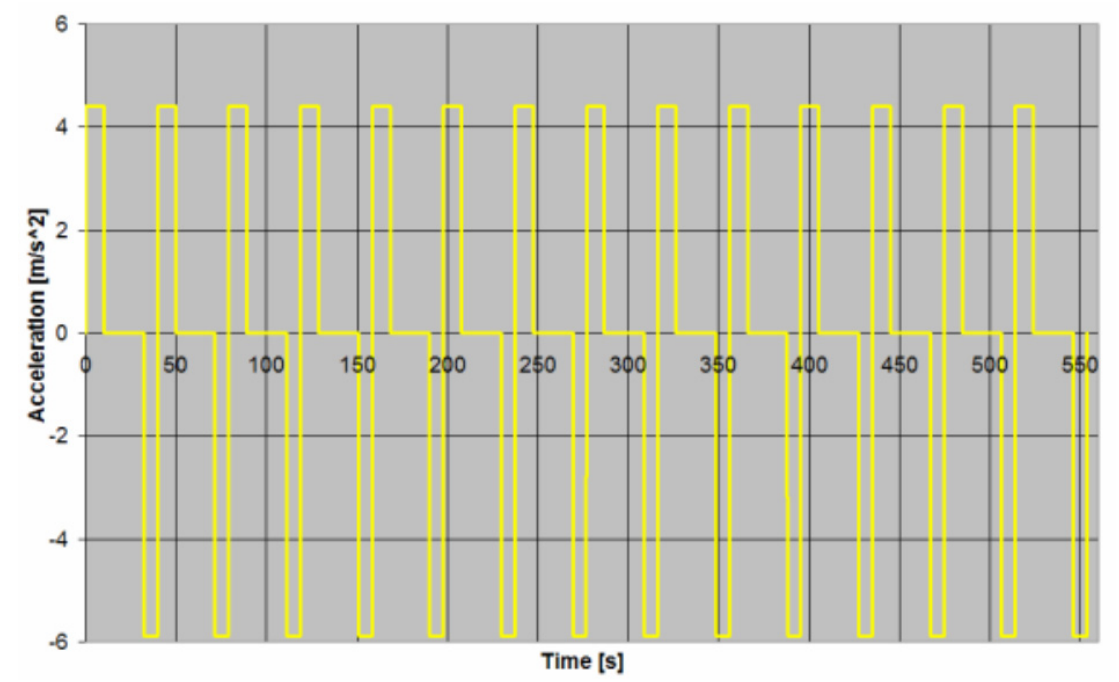

Figure 1: Acceleration versus time in fading test.

The recovery time, $\Delta \mathrm{t}_{\mathrm{r}}$, is established intentionally brief in order to stress the cooling capacity of the brakes. In Tab. 1 , the most important input data of the fading test are summarized.

All the analysed rotors are made of grey cast iron, one of the most common material commercially used for this kind of components. Main physical, thermal and mechanical characteristics are presented in Tab. 2.

To better simulate the real behaviour of the material, the specific heat capacity, the thermal conductivity and the elastic modulus have been considered variable with the temperature, as shown in Figs. 2-4.

As regards the case studies, three ventilated discs and a full one, all by Brembo, have been used. Vented rotors differ from each other in vanes shape. In particular, the three ventilated discs have, respectively, straight, curved and pillar-shaped vanes. Three-dimensional fully parametric CAD models [17] of the discs have been created from 2D technical drawings by Brembo [15], following a typical reverse engineering approach [18]. Irrelevant details have been removed to simplify the FEM models, so reducing the analysis computational time. Main sections of the ventilated discs and a frontal view of the full rotor are shown in Fig. 5. 


\begin{tabular}{lc}
\hline Item & Value \\
Vehicle mass, $m(\mathrm{Kg})$ & 1445 \\
Initial velocity, $\mathrm{V}_{\mathrm{i}}(\mathrm{m} / \mathrm{s})$ & 44.444 \\
Deceleration, $a\left(\mathrm{~m} / \mathrm{s}^{2}\right)$ & 5.886 \\
Single braking elapsed time, $\Delta t(\mathrm{~s})$ & 7.551 \\
Recovery elapsed time, $\Delta \mathrm{t}_{\mathrm{r}}(\mathrm{s})$ & 32 \\
Tyre rolling circumference, $C o(\mathrm{~m})$ & 1.851 \\
Coefficient of adhesion between tyres and road surfaces, $f_{a d}$ & 0.85 \\
Coefficient of friction between pad and disc surfaces, $f_{f}$ & 0.43 \\
Vehicle inertia coefficient, $k$ & 1.1 \\
\hline
\end{tabular}

Table 1: Fading test input data.

\begin{tabular}{lc}
\hline Property & Value \\
Density, $\varrho\left(\mathrm{Kg} / \mathrm{m}^{3}\right)$ & 7200 \\
Thermal expansion coefficient, $a\left(10^{-5} /{ }^{\circ} \mathrm{C}\right)$ & 967 \\
Elastic modulus, $E(\mathrm{GPa})$ & $73-40$ \\
Poisson's ratio, $u$ & 0.27 \\
Thermal conductivity, $\lambda\left(\mathrm{W} / \mathrm{m}^{\circ} \mathrm{C}\right)$ & $59.7-36.4$ \\
Specific heat capacity, $C\left(\mathrm{~J} / \mathrm{Kg}^{\circ} \mathrm{C}\right)$ & $469-945$ \\
\hline
\end{tabular}

Table 2: Main properties of the analysed discs material

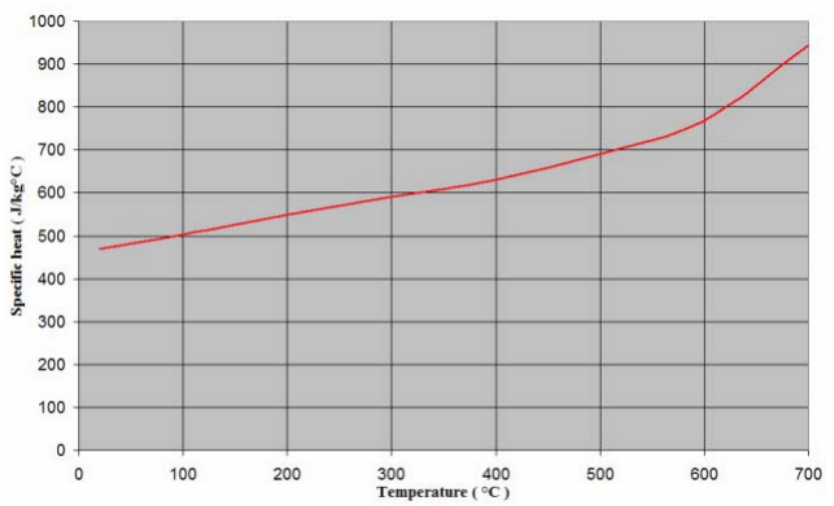

Figure 2: Specific heat capacity vs temperature.

Before the numerical analyses, the original geometries of the discs have been suitably modified and scaled in order to compare successively, in the most consistent way, the results obtained for the different rotors.

For this purpose, the main dimensions (diameters and thicknesses) and the number of vanes have been standardized for all the configurations. In particular, equal values of the:

- external and internal diameters of the annular braking surface,

- hub diameter,

- front and rear disc thickness,

- vanes thickness,

- pad surface, $S_{\text {pad, }}$

have been imposed.

As regard the pad surface, $S_{\text {pad }}$, it has been assumed equal to $1 / 8$ of the annular braking surface of the disc (fig.6). 


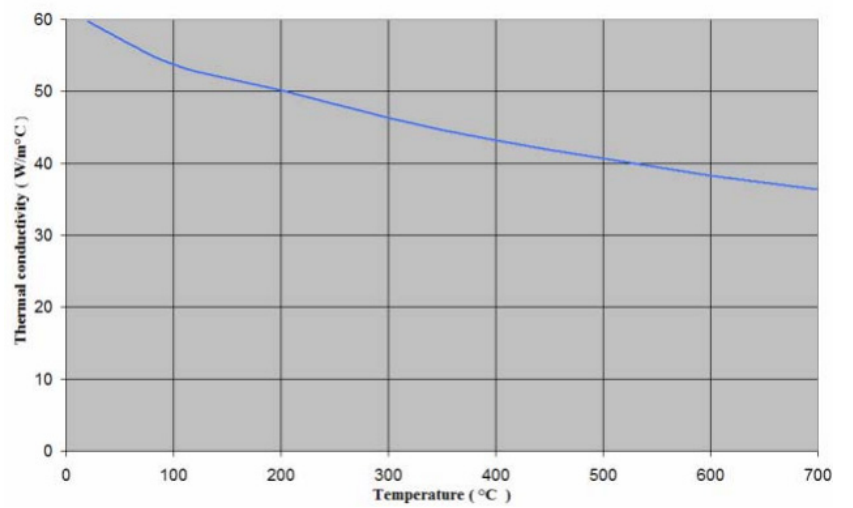

Figure 3: Thermal conductivity vs temperature.
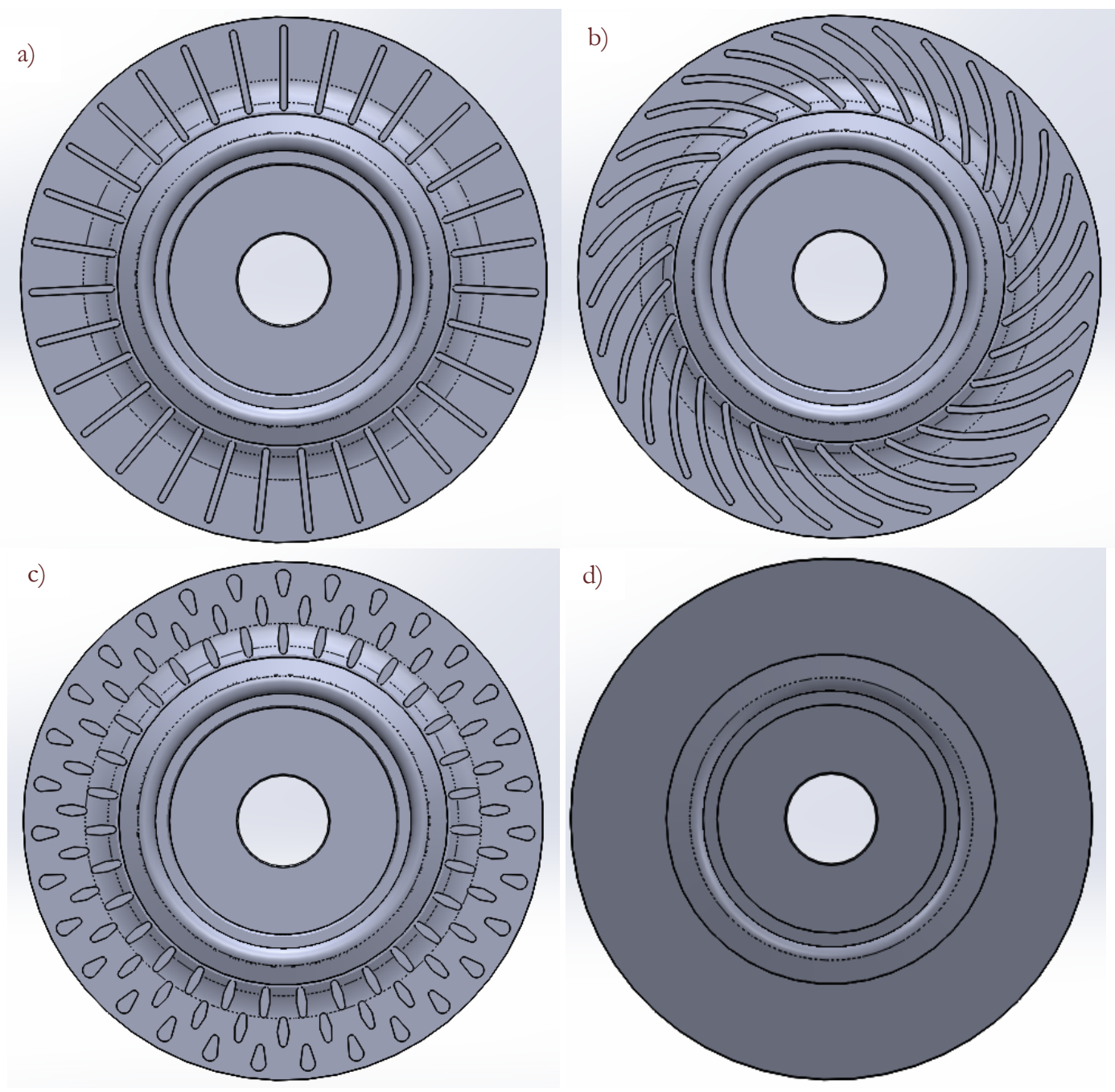

Figure 5: Section views of the straight (a), curved (b) and pillar-shaped (c) vanes discs; frontal view of the full disc (d). 


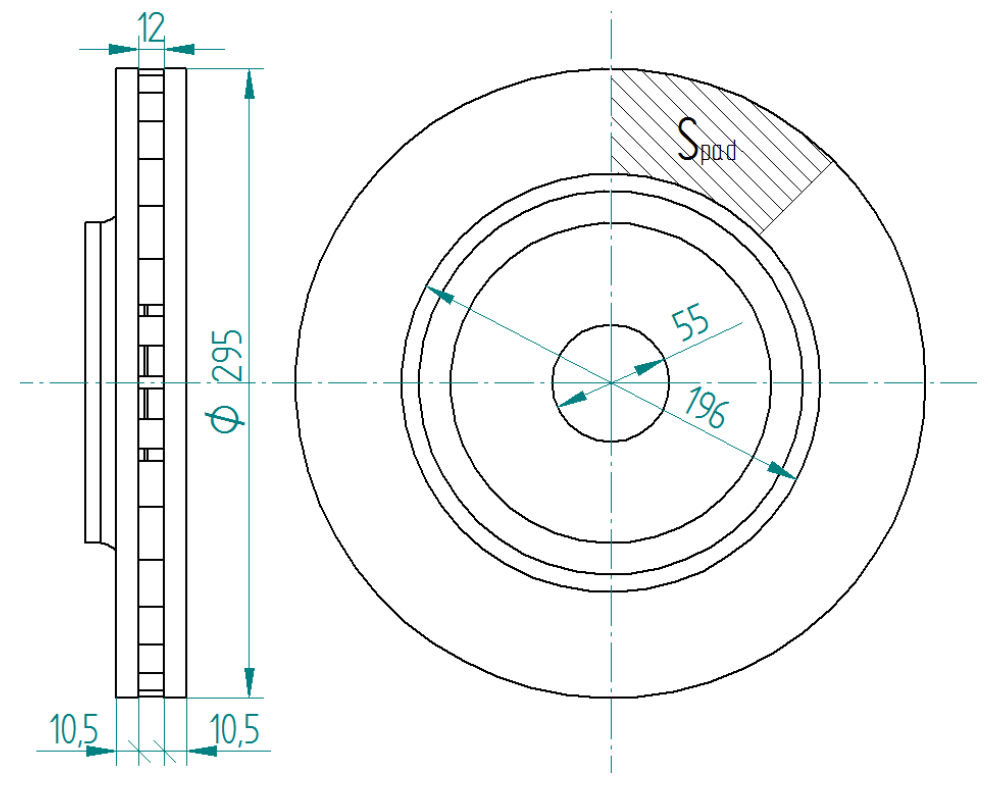

Figure 6: Main dimensions of the discs

The main discs dimensions are summarized in Tab. 3.

\begin{tabular}{lc}
\hline Dimension & \\
External diameter of braking surface $(\mathrm{mm})$ & 295 \\
Internal diameter of braking surface $(\mathrm{mm})$ & 196 \\
Hub diameter $(\mathrm{mm})$ & 55 \\
Front and rear disc thickness $(\mathrm{mm})$ & 10.5 \\
Vanes thickness $(\mathrm{mm})$ & 12 \\
Pad surface, $S_{\text {pad }}\left(\mathrm{mm}^{2}\right)$ & 5475.8 \\
\hline
\end{tabular}

Table 3: Common dimensions of the discs.

\section{HEAT FLUX AND BRAKING FORCE INPUTS}

1 o perform the numerical simulations of the brake-fading test, the working conditions of the thermal and structural analyses have been preliminarily defined. In particular, the specific heat flux at the pads/disc interface and the braking forces have been calculated. All calculations have been made considering the input data reported in Tab.

1.

Since the Ansys FEM code does not allow to setup the disk rotation during a transient thermal analysis, a specific routine has been developed. In particular, the annular braking surface has been subdivided in eight sectors, each one equal to the pad surface $\left(\mathrm{S}_{\mathrm{pad}}\right)$. After, for every single wheel turn, the specific heat flux in a braking sector has been calculated and imposed, following an appropriate timing, to suitably simulate the relative rotational motion between pads and disk.

\section{Heat Flux}

On the basis of the law of conservation of energy, it can be assumed that almost all the kinetic energy of the vehicle during motion is equal to the heat generated after vehicle stops [1,7]. During the braking phase, in fact, due to the friction between pads and disc surfaces, the kinematic energy of a vehicle is transformed into thermal energy. In this study, as 
usually happens [10,19], it has been assumed that the thermal conductivity of the pads material is much smaller than the one of the disc. For this reason, it can be hypothesized that the heat generated during the braking is entirely absorbed by the disc. Basing on these assumptions, the specific heat fluxes on every sector of the disc braking surface have been calculated as follows.

During a braking, the variation of the kinetic energy in a single wheel turn can be calculated as:

$$
\Delta E=\frac{1}{2} m \cdot\left(V_{f}^{2}-V_{i}^{2}\right)
$$

where $V_{f}$ and $V_{i}$ are, respectively, the final and the initial velocity during one wheel rotation.

Since the braking is conducted as uniformly decelerated motion, the variation $\left(V_{f}^{2}-V_{i}^{2}\right)$ is constant, and can be expressed as:

$$
\left(V_{f}^{2}-V_{i}^{2}\right)=2 \cdot a \cdot d=2 \cdot a \cdot C_{o}=\text { constant }
$$

where $\mathrm{d}$ represents the distance covered in a wheel turn, equal to the tyre rolling circumference $\mathrm{C}_{\mathrm{o}}$.

Consequently, also $\Delta E$ has a constant value at every single wheel rotation:

$$
\Delta E=\frac{1}{2} m \cdot\left(V_{f}^{2}-V_{i}^{2}\right)=m \cdot a \cdot C_{o}=\text { constant }
$$

Neglecting both motion resistance and motor braking, the thermal energy, $Q_{\text {wheel }}$, on a single front wheel during a single turn, can be calculated $[7,10]$ as a function of $\Delta E$ :

$$
Q_{\text {whel }}=\frac{1}{2} \cdot f \cdot \Delta E=\text { constant }
$$

where $\mathrm{f}$ is the dynamic load distribution coefficient on front wheels [20].

In order to simplify the setup of the boundary conditions, without affecting the results, it has been assumed the heat flux constant over a single wheel rotation and equal to:

$$
q=\frac{Q_{\text {wheel }}}{\Delta t}
$$

where $\Delta t$ is the wheel turning time. Considering that the braking is a uniformly decelerated motion, $\Delta t$ increases at every single turn of the wheel and, consequently, $q$ varies accordingly.

The routine developed to simulate the relative rotation between pads and disc has required to calculate, from the beginning to the end of the braking, at every wheel turn, the specific heat flux for all the eight sectors in which the braking surface has been subdivided.

To do that, knowing $q$, the specific heat flux in a generic sector of the annular braking surface, equal to $\mathrm{S}_{\mathrm{pad}}$, has been calculated as:

$$
q_{s, \text { pad }}=\frac{q}{8} \cdot \frac{1}{S_{\text {pad }}}=\frac{Q_{\text {wheel }}}{\Delta t} \cdot \frac{1}{8} \cdot \frac{1}{S_{\text {pad }}} .
$$

The graph of $q_{s, \text { pad }}$ vs time, during a complete braking, for one of the eight sectors is shown in Fig. 7. 


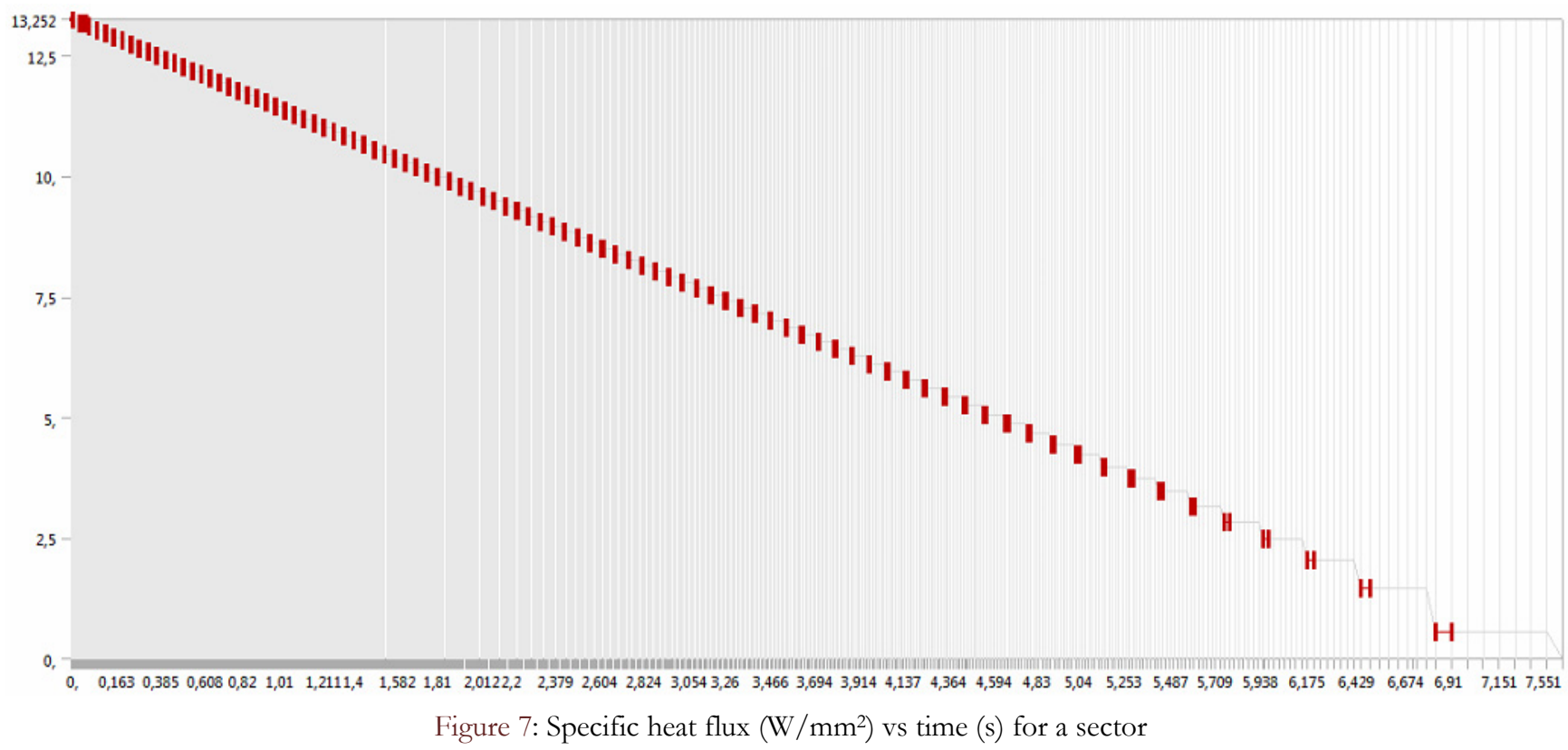

\section{Braking forces}

Braking system works by applying two axial forces that clamp the pads against the disc. In this study, the braking forces have to be enough to arrest the vehicle under the working conditions presented in Tab. 1.

During a braking, the normal $\left(F_{n}\right)$ and tangential $\left(F_{t}\right)$ forces on one front wheel can be expressed as [16,20]:

$$
\begin{aligned}
& F_{n}=f \cdot m \cdot g \cdot \frac{1}{2} \cdot k, \\
& F_{t}=V \cdot f_{a d}=f \cdot m \cdot g \cdot \frac{1}{2} \cdot k \cdot f_{a d},
\end{aligned}
$$

where:

$\mathrm{f}$ is the dynamic load distribution coefficient on front wheels,

$\mathrm{k}$ represents the vehicle inertia coefficient

$\mathrm{f}_{\mathrm{ad}}$ is the adherence coefficient between tyre and road.

The braking torque applied to one wheel can be calculated as [20,21]:

$M_{b}=F_{t} \cdot \frac{C_{o}}{2 \pi}$

consequently, the braking force $F_{\text {pad }}$ (normal force on a single pad) is equal to:

$F_{p a d}=\frac{M_{b}}{f_{f} \cdot d} \cdot \frac{1}{2}$,

where:

$\mathrm{f}_{\mathrm{f}}$ is the disc/pad friction coefficient

$\mathrm{d}$ is moment arm, which value is $125.1 \mathrm{~mm}$. 


\section{SETUP OF NUMERICAL ANALYSES}

1 he fading test has been numerically simulated through a thermo-mechanical coupled analysis. During all the 14 braking/recovery steps, the temperature does not have enough time to stabilize in the disc and, for this reason, transient thermal analyses have been performed. After the thermal analyses, a structural simulation has been setup considering both thermal loads and braking forces on the discs.

The length of every single braking is $7.55 \mathrm{~s}$, whereas the recovery steps are $32 \mathrm{~s}$ length, according to the time between a braking and the next one. During the recovery time simulations, convection is the only applied boundary condition. For all the analysed configurations of the rotors, the convective heat transfer coefficients have been estimated basing on the experiential formulas in literature [16,22], considering an environment (air) temperature equal to $20^{\circ}$.

To simulate the cumulative effect of repeated braking, every thermal transient analysis has been linked with the previous and next ones. In this way, the solution of $\mathrm{i}$-th step represents the input data for the following step and so on. The blocks diagram of the implemented procedure is presented in Fig. 8.

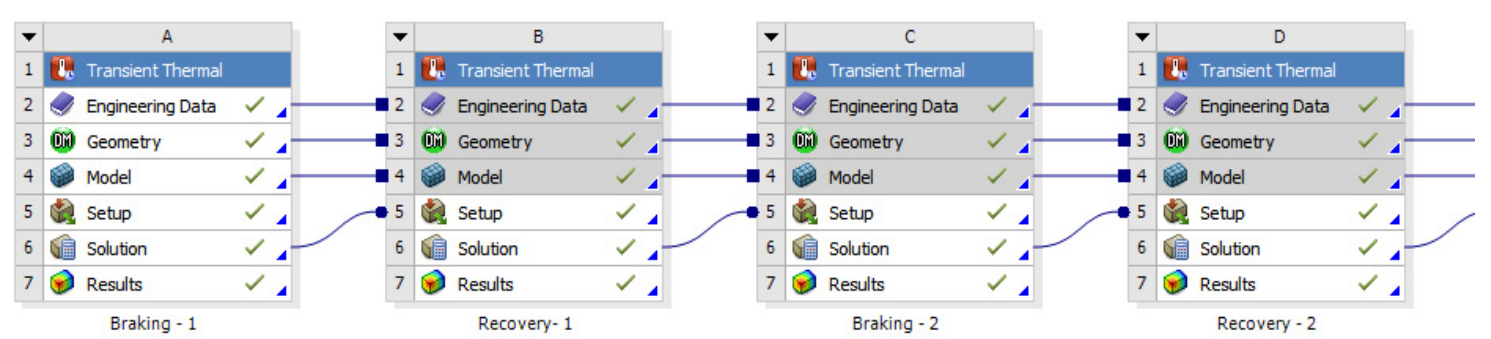

Figure 8: Blocks diagram of the braking/recovery simulations

At the end of the 14th braking, a static structural analysis module has been inserted and linked to the last thermal one. To setup the structural analysis, the temperature distribution over the disc at the end of the last thermal analysis and the braking forces on the pads $\left(F_{p a d}\right)$ have been imposed as boundary conditions. Moreover, also a cylindrical constraint has been applied on the hub of the disks. All FEM models have been meshed with hexahedral elements. The mesh of the straight-vanes disc is shown in Fig. 9.

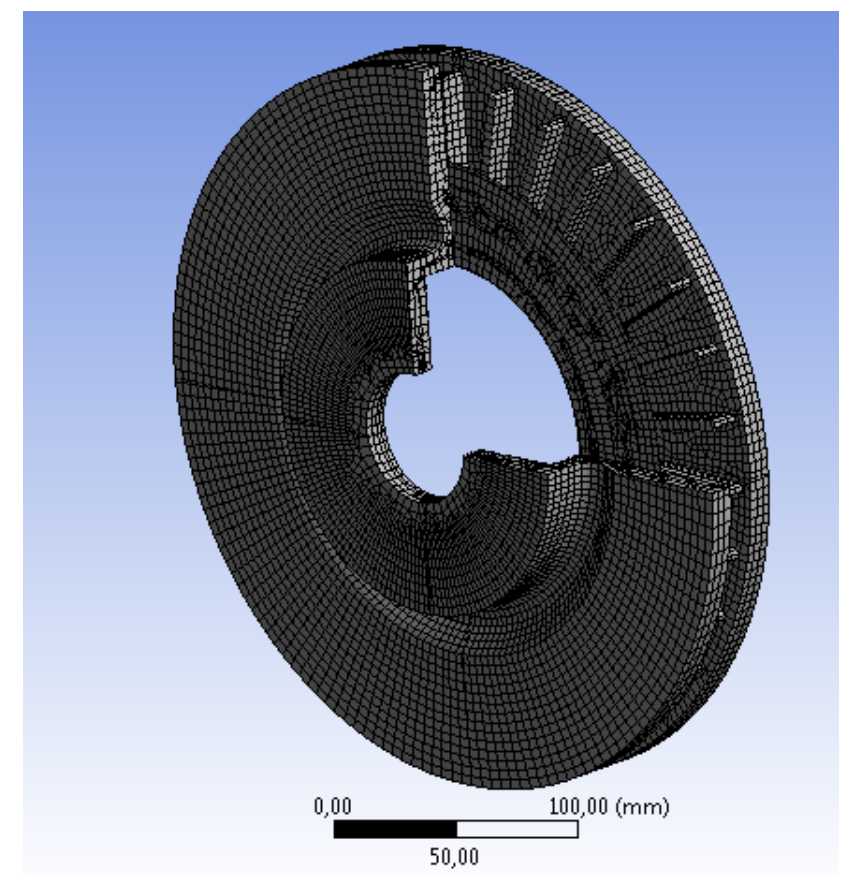

Figure 9: Mesh of the straight-vanes disc. 


\section{RESULTS}

\section{Thermal results}

he plots of the maximum temperatures vs time during the fading test are shown in Fig. 10.

For all the configurations, it can be observed that when braking is taking place, not all the heat generated can be efficiently dissipated and, consequently, disks temperatures remarkably increase.

During the recovery stage, instead, since no more heat is introduced in the system, due to the effect of the convective mechanisms, the maximum temperatures tend to decrease. Nevertheless, as the recovery time is not long enough to restore initial values, temperatures become higher and higher from the beginning to the end of the test.

Analysing the temperatures plots, there is no appreciable difference among the analysed vented discs during the first steps of the fading test. Going forward in the test, instead, temperatures curves gradually diverge among them (fig. 11). Maximum temperature values at the end of the last braking are, respectively, $889^{\circ} \mathrm{C}$ for the straight-vanes disc, $841^{\circ} \mathrm{C}$ for the curved configuration and $875^{\circ} \mathrm{C}$ for the pillar-shaped disc.

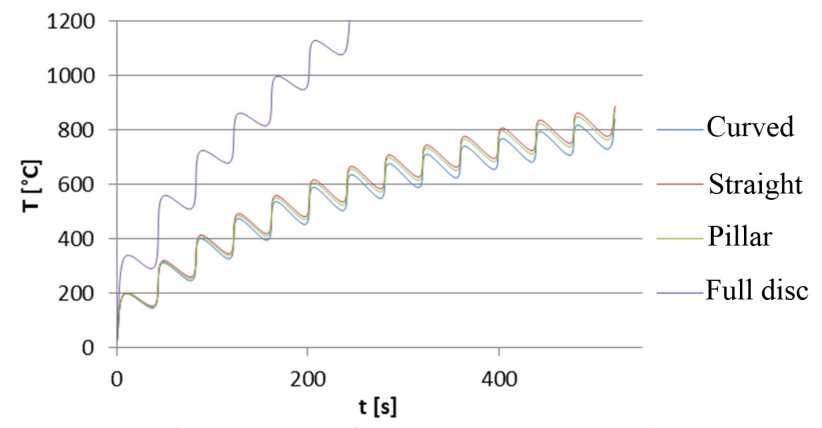

Figure 10: Maximum temperature vs time.

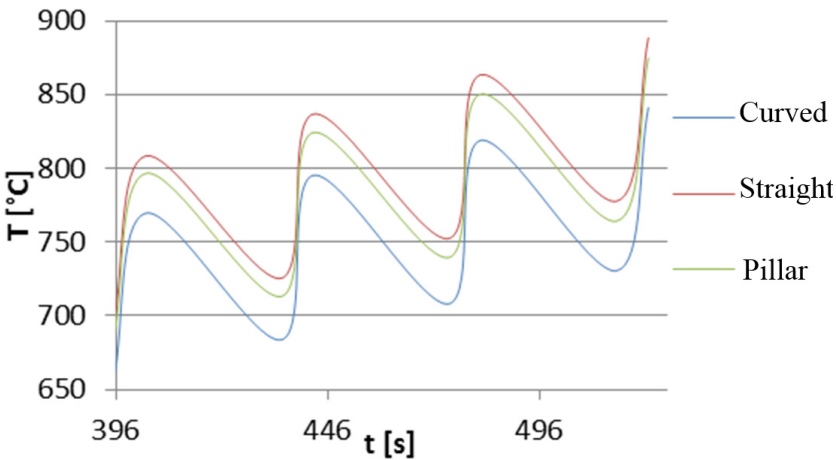

Figure 11: Trends of max temperature in the last phases of fading test.

Concerning the full disc, after completing the sixth braking, the maximum temperature has reached a value slightly above $1100^{\circ} \mathrm{C}$, which is over the safety threshold value [23] for this kind of application. For this reason, numerical results of the full disc have not further considered after the sixth arrest. Nevertheless, this result is useful to quantify the performances difference between the ventilated disks and the full one, so confirming the use of this last kind of rotor for applications in which moderate braking performances are required.

As regards the temperature distribution maps, it can be observed that braking surfaces deal with the highest values. The maximum temperature zones are located on the quarters corresponding to the couple of pads. Fig. 12 shows the temperature maps on the external surfaces and the internal vanes of the disks. The maps of temperature distribution on the external surfaces are quite similar among the analysed discs. The efficiency of the vanes in dissipating heat is also appreciable by analysing the temperature distributions on the internal and external surfaces of the discs. In conclusion, with reference to the thermal results, curved vanes represent the best solution because they allow better airflow propagation and, consequently, the maximum temperature reaches a lower value than the straight and the pillar-shaped vanes discs. 


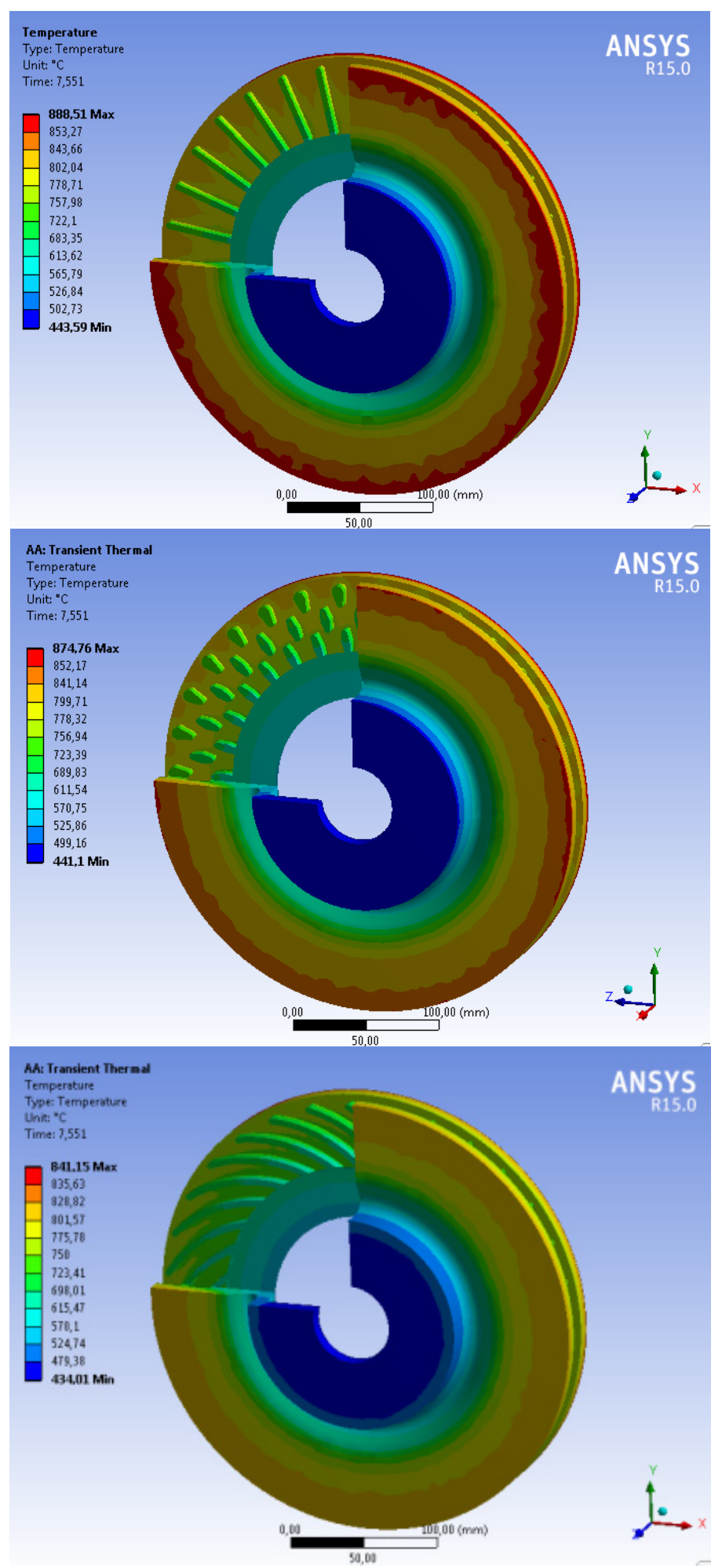

Figure 12: Temperature maps at the $14^{\text {th }}$ braking on straight (left), pillar-shaped (centre) and curved-vanes (right) disc

\section{Mechanical results}

Maps of Von Mises stresses at the end of the fading test are shown in Fig. 13. The trace due to the pads, because of the braking forces and the thermal gradient, is visible both on the pads-rotor interfaces and on their corresponding vanes (fig. 13-14). 

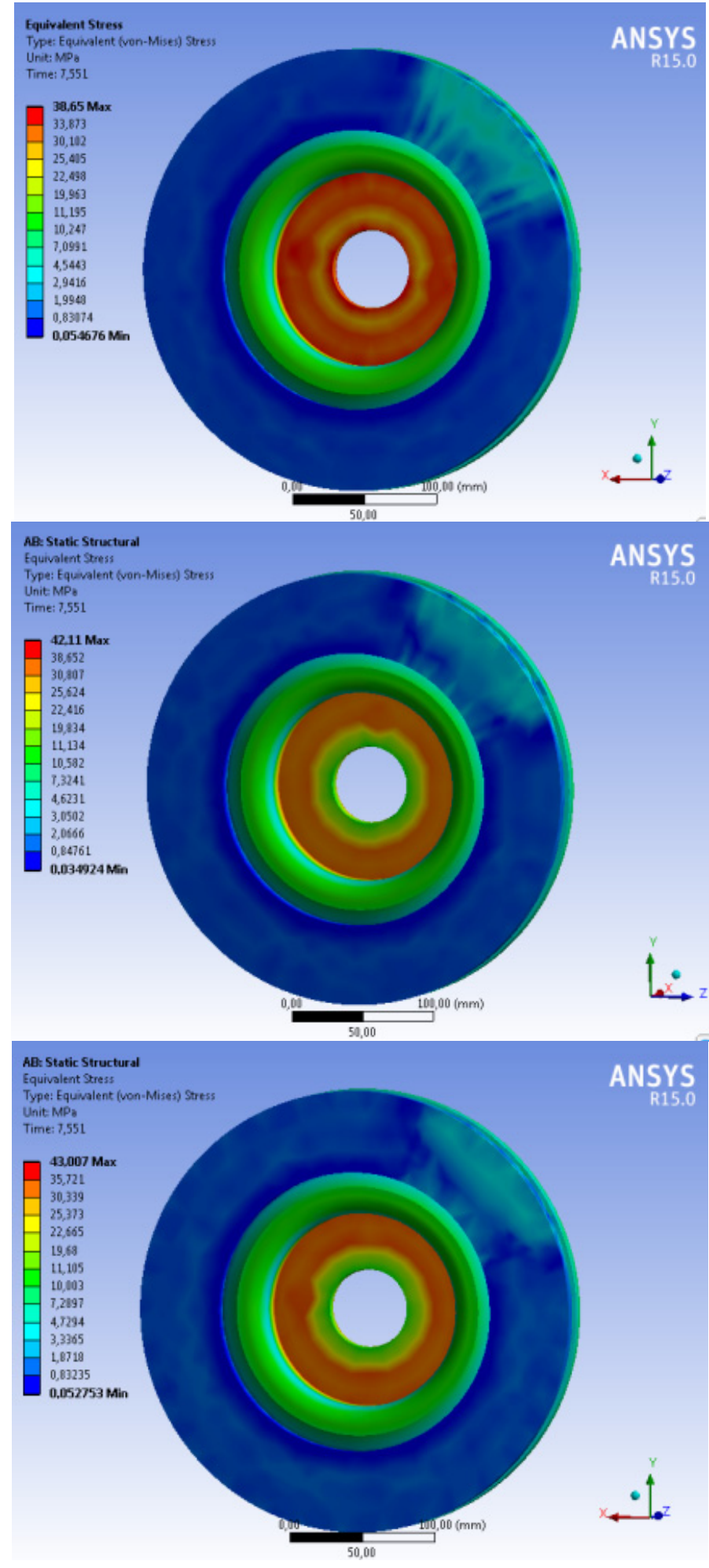

Figure 13: Von Mises stress maps at the $14^{\text {th }}$ braking on straight (left), pillar-shaped (centre) and curved-vanes (right) disc.

It can be also observed that the effect of pads is restricted to a small area, substantially the same as $\mathrm{S}_{\mathrm{pad}}$, and it runs out quickly (fig. 13) along the circumference of the braking surface. Moreover, high stress values can be found around the hubs, most likely due to the considerable temperature gradients between the outer and inner parts of the rotors and the 
cylindrical constraints, which limit the thermal expansion. Stress distributions over the discs are uniform. Curved and pillar-shaped vanes rotors have similar behaviours, both in terms of stress distribution and maximum values reached on them, respectively equal to about $43 \mathrm{MPa}$ and $42 \mathrm{MPa}$.

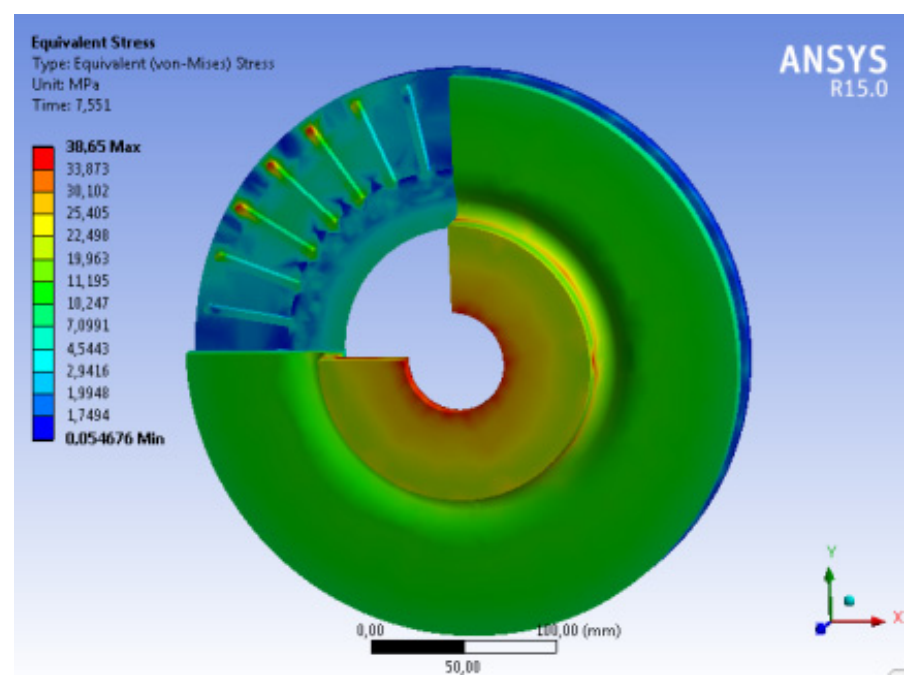

Figure 14: Von Mises stress maps on the internal vanes of the straight vanes disc.

Better results have been obtained with the straight-vanes disc, whose maximum stress value is about $39 \mathrm{MPa}$, slightly lower than the other two configurations.

In an exhaustive study of the performances of brake discs, it is also important to check the structural deformations. In this kind of applications, in fact, thermo-mechanical strains must be under control because excessive values could induce an irregular contact between pads and disc, so compromising the correct functionality of the braking system [8]. In the analysed rotors, strains develop mainly along the radial direction, due to the increase of temperature from the hub to the outer part of the disc. Highest deformations have been found at the pads-disc interface. This area is particularly stressed because of the applied braking forces and the thermal flux, which causes locally considerable thermal gradients.

Fig. 15 represents amplified lateral views of the discs radial deformations; it is possible to perceive how discs start to curve themselves, turning into a cone shape.

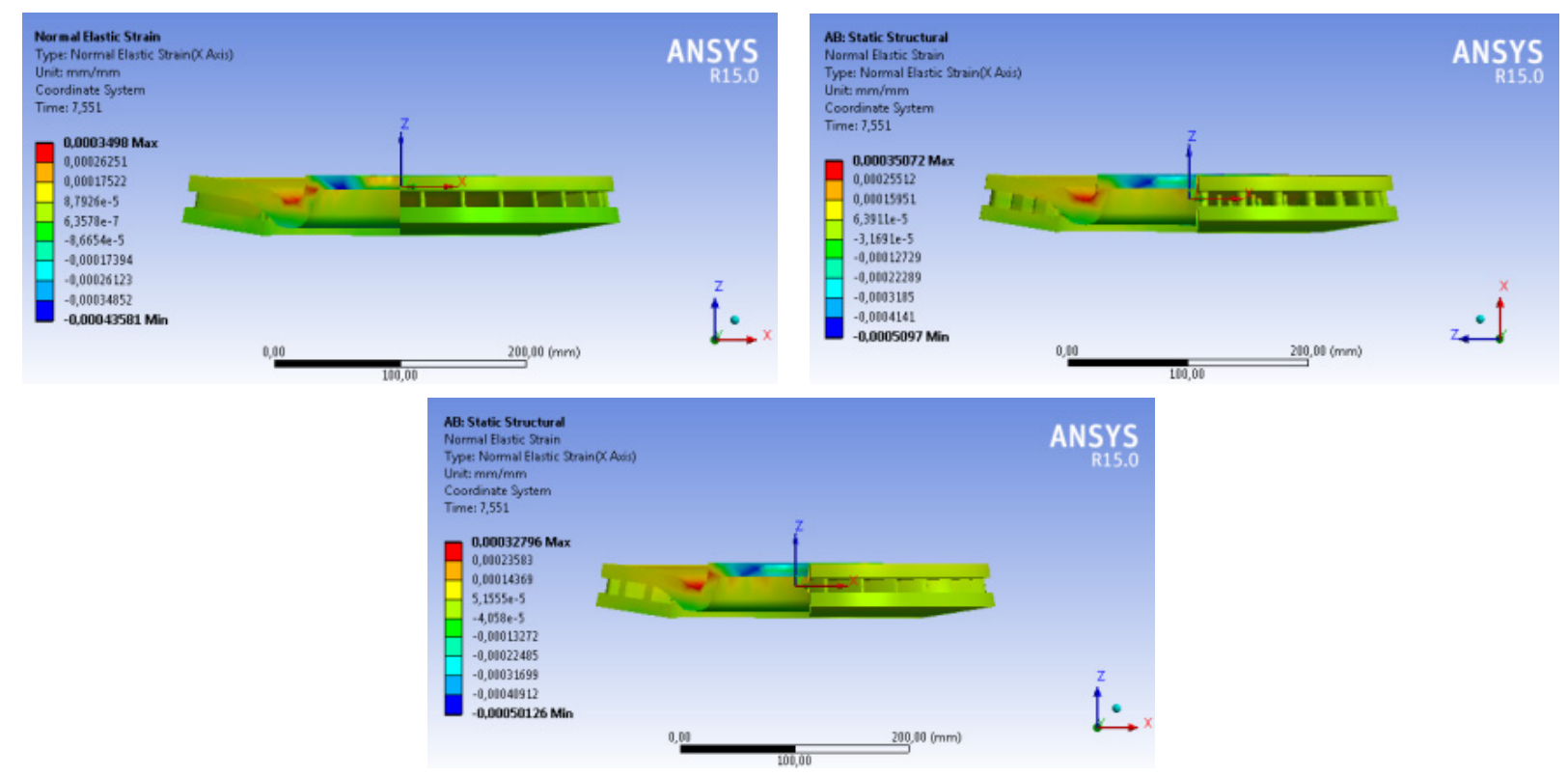

Figure 15: Radial deformations on straight (left), pillar-shaped (centre) and curved-vanes (right) disc 
However, from data in Tab. 4, it can be observed that the thermo-mechanical strains reach very low values, so demonstrating a very good behaviour of the analysed discs throughout the brake fading test.

\begin{tabular}{lcc}
\hline Disc type & Min $(\mathrm{mm} / \mathrm{mm})$ & Max $(\mathrm{mm} / \mathrm{mm})$ \\
Straight & -0.00043581 & 0.0003498 \\
Pillar & -0.0005097 & 0.00035072 \\
Curved & -0.00050126 & 0.00032796 \\
\hline
\end{tabular}

Table 4: Minimum and maximum radial strain values.

\section{CONCLUSIONS}

B ehaviour of different types of disc brake rotors has been investigated by means of coupled thermo-mechanical numerical analyses. Very hard working conditions have been imposed to the discs in order to evaluate and to compare their performances when subjected to fourteen repeated hard braking. Three ventilated discs (respectively with straight, curved and pillar-shaped vanes) and a full one have been studied. This last has shown a poor behaviour, reaching an out-of-use condition after the sixth braking. All the analysed vented rotors, instead, have shown very good performances in terms of heat transfer, so allowing their safe use in extreme braking conditions.

By comparing the temperature distribution maps, it can be stated that the best disc is the one with curved vanes, whereas the worst one is the straight-vanes disc. This last one reaches a maximum temperature of about $890{ }^{\circ} \mathrm{C}$, which is appreciably higher than the temperature reached by the curved-vanes disc $\left(840^{\circ} \mathrm{C}\right)$.

In terms of stresses, instead, previous results are completely reversed. The best disc, in fact, is the straight vanes one, which reaches a maximum value of Von Mises stress of about $38 \mathrm{~N} / \mathrm{mm}^{2}$, whereas the curved-vanes disc has a maximum value of $43 \mathrm{~N} / \mathrm{mm}^{2}$. However, these values are much lower than the material yield strength so, under the imposed working conditions, the discs are not much stressed. Also with regard to the deformations, all the analysed discs have shown very good performances, reaching very low value of strains.

For these reasons, considering that the maximum stress and strain values over the discs are quite low, the discriminating and most important factor in the choice of the best solution should be related to the thermal results. High values of temperature, in fact, can affect the rotor material properties and, consequently, the right functionality of the whole braking system. Then, basing on the obtained results, it could be stated that, among the analysed rotors, the best solution for very hard repeated braking is the curved-vanes disc.

The methodology implemented in this work could be effectively used also during the design phase in order to evaluate, in a preliminary stage, the best shape of the brake rotor depending on the planned working conditions. Thanks to the developed parametric CAD models of the discs, in fact, it is possible interfacing the FEM numerical models and an optimization software with the aim to identify the optimal solutions in terms of shape and number of the vanes, rotor thicknesses, etc.

\section{REFERENCES}

[1] Milenković, P. D., Jovanović, S. J., Janković, A. S., Milovanović, M. D., Vitošević, N. D., Đorđević, M. V., Raičević, M. M., The Influence of Brake Pads Thermal Conductivity on Passenger Car Brake System Efficiency, Thermal Science, 14 (2010) S221-S230

[2] Belghazi, H., Analytical Solution of Unsteady Heat Conduction in a Two-Layered Material in Imperfect Contact Subjected to a Moving Heat Source, Ph. D. thesis, University of Limoges, Limoges, France, (2010).

[3] Mackin, T. J., Noe, S. C., Ball, K. J., Bedell, B. C., Bim-Merle, D. P., Bingaman, M. C., Zimmerman, R. S., Thermal cracking in disc brakes, Engineering Failure Analysis, 9(1) (2002) 63-76.

[4] Nakatsuji, T., Okubo, K., Fujii, T., Sasada, M., Noguchi, Y., Study on Crack Initiation at Small Holes of One-piece Brake Discs (No. 2002-01-0926), SAE Technical Paper (2002).

[5] Gao, C. H., Lin, X. Z., Transient temperature field analysis of a brake in a non-axisymmetric three-dimensional model, Journal of Materials Processing Technology, 129(1) (2002) 513-517. 
[6] Gao, C. H., Huang, J. M., Lin, X. Z., Tang, X. S., Stress analysis of thermal fatigue fracture of brake disks based on thermomechanical coupling, Journal of tribology, 129.3 (2007) 536-543.

[7] Talati, F., Jalalifar, S., Analysis of heat conduction in a disk brake system, Heat and mass transfer, 45(8) (2009) 10471059

[8] Valvano, T., Lee, K., An Analytical Method to Predict Thermal Distortion of a Brake Rotor, SAE paper 2000-010445, (2000).

[9] Belhocine, A., Bouchetara, M., Thermomechanical behavior of dry contacts in disc brake rotor with a grey cast iron composition, Thermal Science, 17(2) (2013) 599-609.

[10] Hwang, P., Wu, X., Investigation of temperature and thermal stress in ventilated disc brake based on 3D thermomechanical coupling model, Journal of mechanical science and technology, 24(1) (2010) 81-84.

[11] Belhocine, A., Cho, C. D., Nouby, M., Yi, Y. B., Abu Bakar, A. R., Thermal analysis of both ventilated and full disc brake rotors with frictional heat generation. Applied and Computational Mechanics, 8.1 (2014) 5-24.

[12] Galindo-Lopez, C. H., Tirovic, M., Understanding and improving the convective cooling of brake discs with radial vanes, Journal of Automobile Engineering, 222(7) (2008) 1211-1229.

[13] Ingrassia, T., Nigrelli V., Design optimization and analysis of a new rear underrun protective device for truck, 8th International Symposium on Tools and Methods of Competitive Engineering, TMCE, 2 (2010) 713-725.

[14] Mineo, C., Cerniglia, D., Pantano, A., Numerical study for a new methodology of flaws detection in train axles, Ultrasonics, 54(3), 2014, 841-849.

[15] Brembo GT, Technical Information, (2014).

[16] Gotowicki, P. F., Nigrelli, V., Mariotti, G. V., Aleksendric, D., Duboka, C., Numerical and experimental analysis of a pegs-wing ventilated disk brake rotor, with pads and cylinders, 10 th EAEC Conference -5 (2005).

[17] Ingrassia, T., Mancuso, A., Nigrelli, V., Tumino D., A multi-technique simultaneous approach for the design of a sailing yacht, Int. J. Interact. Design Manuf., (2015). DOI: 10.1007/s12008-015-0267-2.

[18] Nalbone, L., Adelfio, R., D’arienzo, M., Ingrassia, T., Nigrelli, V., Zabbara, F., Paladini, P., Campi, F., Pellegrini, A., Porcellini, G, Optimal positioning of the humeral component in the reverse shoulder prosthesis, Musculoskeletal surgery, 98 (2) (2014) 135-142.

[19] Belhocine, A., Mostefa B., Simulation of fully coupled thermomechanical analysis of automotive brake discs, Simulation, 88.8 (2012) 921-935.

[20] Jazar, R. N., Vehicle dynamics: theory and application, Springer Science \& Business Media, (2013).

[21] Walker J., The Physics of Braking Systems, StopTech LLC, (2005).

[22] Limpert, R., Brake design and safety, Second ed., Warrendale, Society of Automotive Engineers Inc, USA, (1992).

[23] Adamowicz, A., Grzes, P., Influence of convective cooling on a disc brake temperature distribution during repetitive braking, Applied Thermal Engineering, 31(14) (2011) 2177-2185. 